\title{
An Easy Test for Bacteria in Milk and Cream
}

(Barthel's Reductase Test Improved)

BX

\section{HUGO JONE}

Chief Chemist and Bacteriologist of the Empire State Dairy Co., Brooklyn, N. Y, late Chief Chemist of the Chicago Health Department.

Price 50 Cents

(Prepaid)

HUGO JONE

P. O. Box 37 , Station A, Brooklyn, N. Y.

1915 


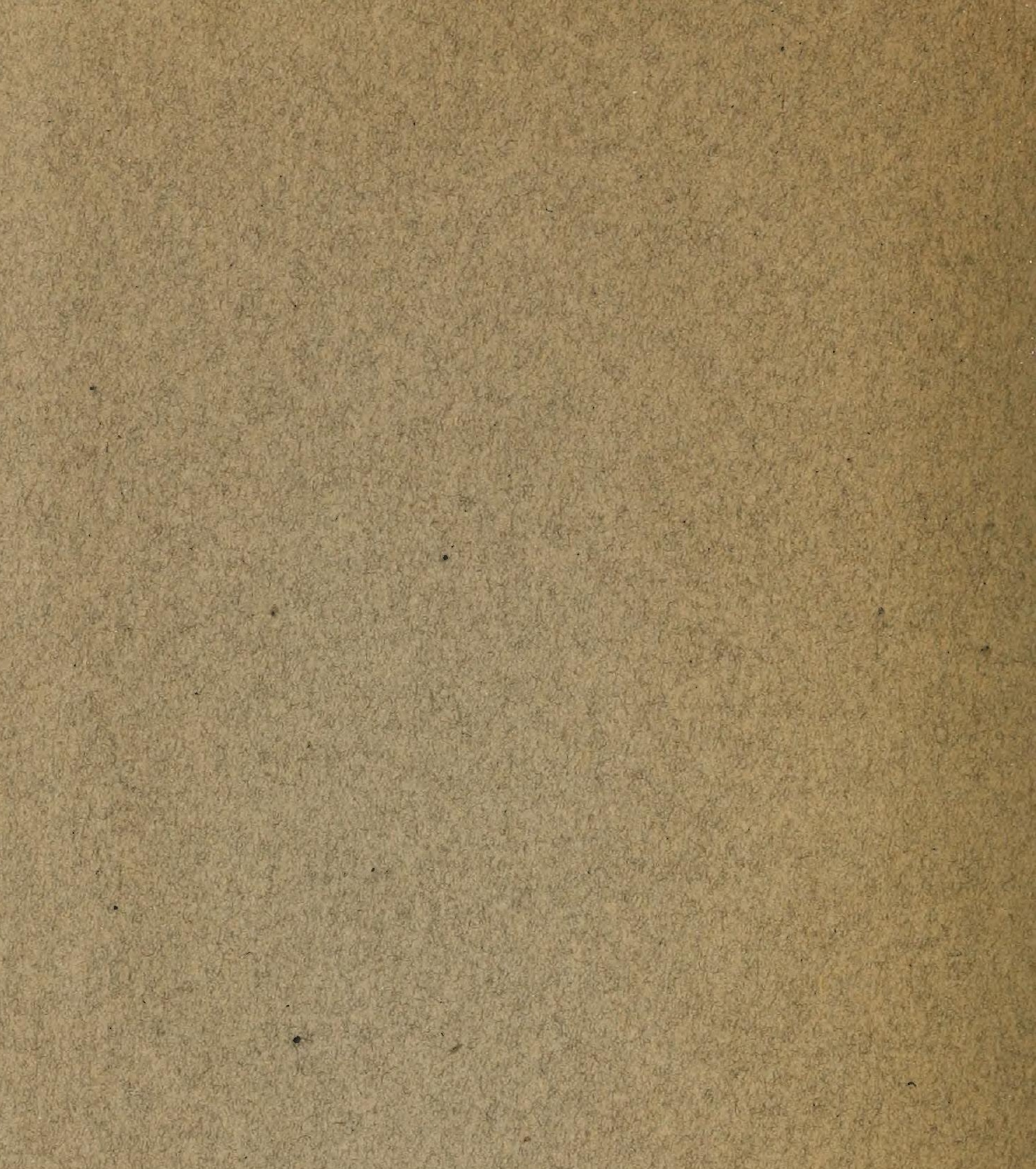

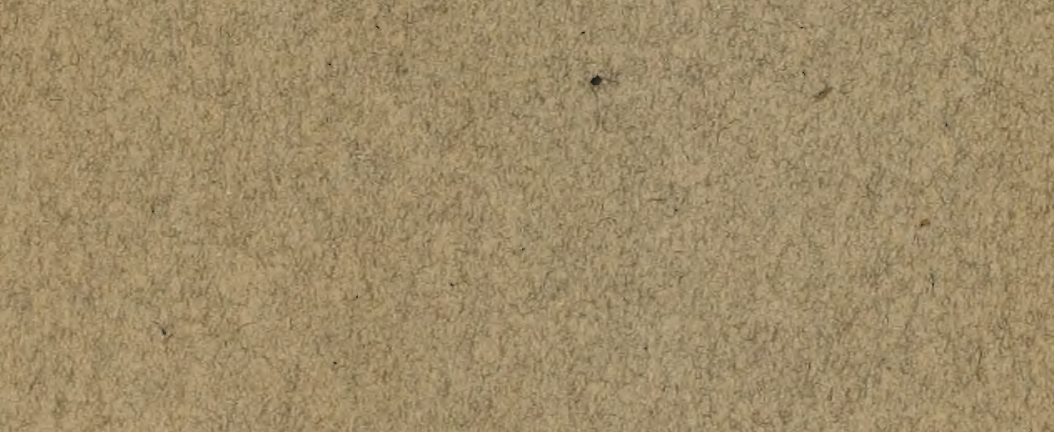

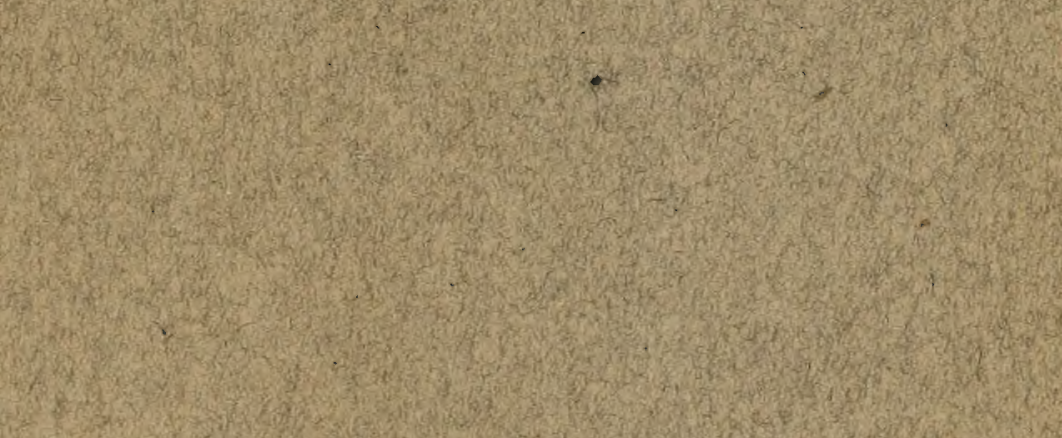

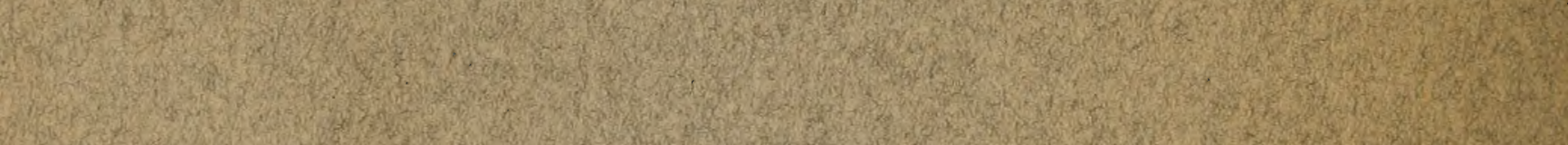

(20.7.

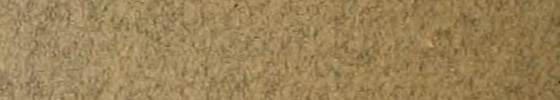

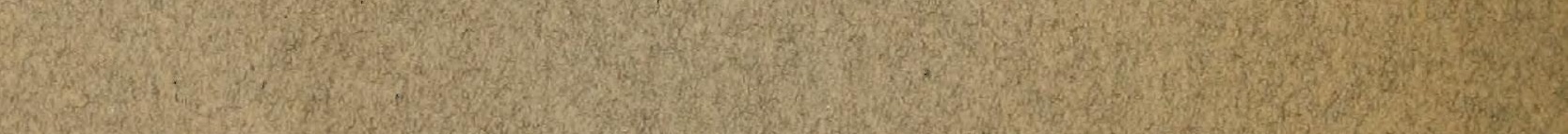
1. 1.

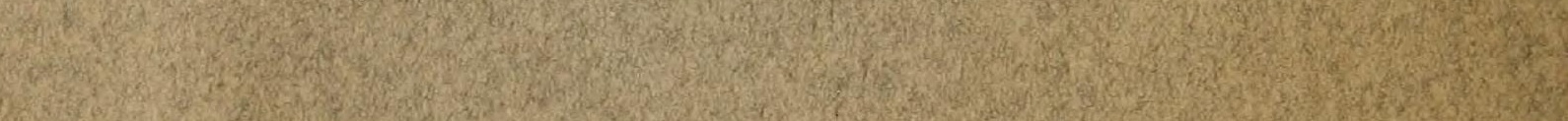

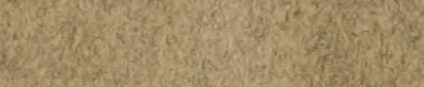

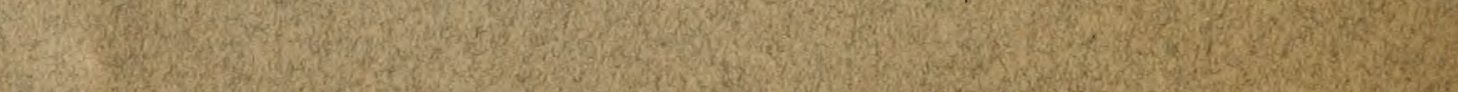
2. 160.

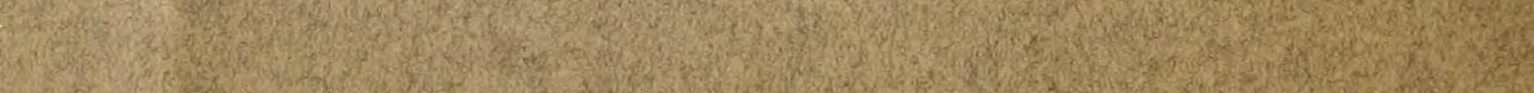
W.

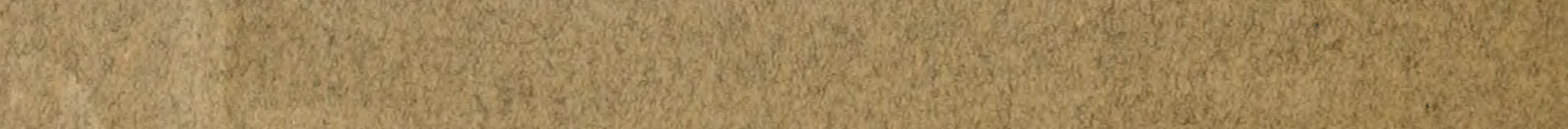




\title{
An Easy Test for Bacteria in Milk and Cream
}

(Barthel's Reductase Test Improved)

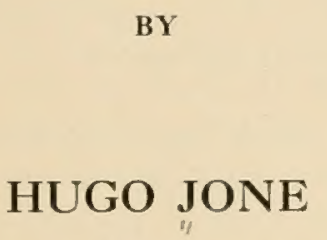

Chief Chemist and Bacteriologist of the Empire State Dairy Co., Brooklyn, N. Y., late Chief Chemist of the Chicago Health Department.

\section{Price 50 Cents \\ (Prepaid)}

HUGO JONE

\author{
P. O. Box 37, Station A, Brooklyn, N. Y.
}




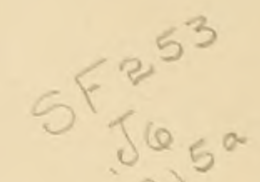

\section{ERRATA}

Page II, lines 2f and 25: The words "If there is any, the mixing was not done thoroughly." ase to be omitted.

Page II, line 27: The avords "and placed into a wire basket liaving a layer of cotton at the bottom" are to be omitted.

Page I9, line I2 from the bottom: The words "If, in addition to using $8 \mathrm{cc}$ of blue solution, the air is excluded from the tubes as directed on page 24," are to be inserted so as to precede the words: "the results obtained in this manner are quite accurate and may be relied on as indicating correctly the extent of the bacterial activity in the milk." 


\section{INTRODUCTION.}

The problem of improving the sanitary quality of a milk supply is incapable of solution so long as there is not a simple test available for determining approximately the bacterial contents in the country. No amount of testing done in the city, at the point of consumption, can ever prevent the most serious pollution of the milk, which is that occurring previously, in the country, at the point of production. Much of the testing must be done in the country. If it is omitted, the creamery manager does not know which of the farmers that furnish milk to him, is to be held responsible whenever the bacteria run high in the mixed milk which he ships to the city. Before the cause of pollution can be removed, it must of necessity first be located. This cannot easily be done without a test. It is true that the inspectors sent out by the creameries to score the dairies discover some causes of pollution. But the inspectors need a test to determine beforehand which of their numerous dairies require inspection the most. Furthermore, experience shows that the inspectors are frequently deceived by the farmers. A farmer may have his dairy in first class condition when the inspector is around and yet deliver milk which runs excessively high in bacteria, without being discovered by the inspector. He may, for instance, feed sour ensilage during the milking, or keep his evening's milk at $75^{\circ} \mathrm{F}$. instead of $45^{\circ} \mathrm{F}$. over night in summer. So long as a few pieces of ice are put between the cans just before delivery, the inspector is easily cheated. His thermometer certainly fails to detect the excessive number of bacteria in such milk. The color test is the only practical way to locate the trouble. Actual experience proves this.

Over ten thousand samples of milk were tested, at receiving stations in the country, by the color test after my directions, during a period covering two years. These tests have been so successful for the purpose of locating the causes of high bacteria that milk dealers who had not used the test, but who had heard of it, quickly adopted the color test for their own creameries.

Furthermore, well known sanitarians and authorities on milk hygiene made inquiries concerning the test, as improved by me.

Under these conditions, I am sure I am complying with a general demand in publishing a detailed description of the test as improved, and directions for making it.

These directions, as will be noted, are so specific and so simple that every creamery man, including those who never had any previous experience in laboratory work, will be able to make the test without further instructions.

To the bacteriologists and chemists who may read my directions, I beg to apologize for using so simple a language and making statements of facts which are most elementary and well known to them. As thousands of creamerymen, including those who are without experience, are expected to use my directions, I believe I am right in giving elementary instructions, even at the risk of making those directions tiresome to the professional laboratory men. As the latter are comparatively few in number, the harm done by excessive simplicity will not be serious.

It will be noticed that this publication is designed to meet the needs of the milk dealers, creamery employees, condensary employees and others interested, not only as regards contents, but also as regards form.

My statement that the color test, or reductase test, is the only practical test for locating the cause of high bacteria in the country, is amply corroborated by authorities whose judgment cannot be questioned. For instance, Dr. H. C. Campbell of the patho- 
logical division of the U. S. Bureau of Animal Industry, an expert in milk hygiene, in speaking of the reductase, or reduction test and other biochemic tests, in the annual report of the bureau, for 1911, after experimenting with them, comments on these tests as follows:

"The reduction test agreed in most instances with the bacterial count; that is, whenever the sample was reduced in a short time, the bacterial count was high."

"The biochemic tests used are simple in their technique. The results obtained are practically as good as those shown by plating, so far as estimating the number of bacteria is concerned."

"These tests, if applied at the dairy or site of milk production, would greatly aid the health officials in controlling a milk supply."

"In all pathological processes of the udder the reductase properties are increased."

Dr. Wm. Ernst, director of the milk control station at Munich; Dr. John R. Mohler, chief of the pathological division, U. S. Bureau of Animal Industry, and Dr. A. Eichhorn, senior bacteriologist of the same division, in their "Text Book of Milk Hygiene", published in 1915, make the following statements regarding the reductase test:

"Very valuable results are obtained with the reductase test when conducted in connection with the microscopic examination of the sediment."

"As already mentioned, for practical control work the counting of bacteria may be omitted. In this work the reductase test offers a quicker determination of the spoiled condition of the milk."

". . . If (in Müller's experiments) sour milk or cow manure was added to fresh milk, the time of reduction was hastened. He therefore proved that all factors which favorably influence bacterial growth, hasten the reduction."

"The methylene reductase test gives very good information relative to bacterial multiplication."

Manifestly, the extraordinary usefulness of the reductase test is recognized by the leading authorities on milk hygiene. There is a pressing need for a simple, easy, and rapid test for determining the sanitary quality of milk at all creameries, condensaries, dairies and similar places in the country, and the reductase test answers the purpose much better than any other test in existence.

In sharp contrast with the favorable comment of the experienced laboratory men is the comment which comes from superficial and inexperienced observers. Young students and others who had little or no experience in laboratory work, naturally failed to get correct results, chiefly because they did not prepare the methylene blue solution properly. Their technique was faulty because they could not devise their own technique, while the published directions failed to mention the necessary points of technique in making the solution and the test. Their failure to get correct results has evidently no weight in judging the merits of the test. The test can certainly not be held responsible for the mistakes of beginners who misused it at a time when elementary instructions for making it were not yet available. This does not say, however, that the test could not be improved in other respects. Both, the instructions and the test needed improvement. The proper thing to do was evidently to give elementary instructions for making the test. This is what I have undertaken to do. The test itself needed improvement as regards the amount of methylene blue used. In this respect, criticism of the old form of the test hitherto in use may have been justifiable to a certain extent. Realizing that the reductase test is the only test in existence which is simple enough to be used in the country, and that it was badly needed, I undertook to improve it, and the thousands of results obtained with the improved form show that I was more or less successful. 
It may be surmised that the improvements I made on the test are superfluous because experienced laboratory men could get satisfactory results without such improvements. This is, however, not the case. For instance, without a chemical standardization, the strength of the methylene blue solution was bound to vary, even in the hands of an expert, so long as it was based on saturation in alcohol or a similar solvent. A saturated solution made in summer is apt to be stronger than one made in winter, since warm alcohol dissolves more methylene blue than cold alcohol. Furthermore, the admixture of foreign substances sometimes found in methylene blue may also produce a variation. The chemical standardization is therefore necessary even if errors in technique are avoided. It secures more accurate results.

The "Double Time Test" and the bacteriological regulation of the amount of methylene blue used will also be found helpful in obtaining more accurate results.

Thus the improvements and the elementary directions will enable both, the experts and the beginners, to get better results hereafter.

The plating test with agar is a failure in the country for more reasons than one. Aside from the excessive first expense for the complex equipment used in this test, the current expenses are high for the reason that only a professional laboratory man can be relied on as furnishing correct results. Beginners who believe the results they obtain to be correct, are nearly always mistaken. The test has sometimes failed to give correct results in the hands even of the most expert bacteriologists, as Dr. H. W. Conn, the well known specialist in agricultural bacteriology, has shown. This test is even more in need of an improvement than the reductase test had been. With all the money spent on this test, little is accomplished.

In most creameries it would be impossible anyway to use the test successfully even for a professional bacteriologist, since the equipment is never complete. It is for instance difficult to see how an incubator could be kept at constant temperature in a village where neither gas nor an electric current is available. An alcohol lamp would have to be used the same as in the case of the reductase test, with this difference, however, that it is practical to use it in day time for the reductase test, but quite impractical to use it at night for the incubator.

Even this is not yet the last of the disadvantages connected with the plating test. If the creamerymen had to wait 48 hours for the results, as in the plating test, they would fail to locate the causes of those pollutions which disappear in less than that time. They could not reject polluted milk delivered to them on the strength of the plating test, since the milk has to be either rejected or accepted in much less time than 48 hours.

Furthermore, the plating test lost much of its former value as an index of the sanitary quality of raw milk from the time on that pasteurization of milk became general. As the bacteria are killed anyway by pasteurization, the real pollution in the finished pasteurized milk does not consist in bacteria, but in the metabolic compounds left behind by the bacteria. The amount of these metabolic compounds should be determined by exact methods of quantitative chemical analysis and not by any of the biological methods, each of which is more or less inexact. The number of live bacteria, even if it were determined accurately, fails to measure the amount of metabolic compounds correctly for the further reason that these compounds are largely derived from the dead bacteria which in winter are so numerous, and which, evidently, do not show up at all in the plating test. The number of live bacteria, in other words, is out of proportion with the real pollution. 
I do not see how any intelligent manager or director of a milk company can seriously consider the plating test for general adoption in the country stations. I know well that it is desirable to use the same test which the officials use. However, the days of the plating test, as the exclusive official test for raw milk to be pasteurized, are numbered. For that insignificant portion of market milk which is sold raw to the consumer, the plating test may remain a valuable index of the sanitary quality, but not for raw milk to be pasteurized. Conscientious officials will admit that the plating test is not fit to be made the sole basis of legal prosecution for such milk, since it is misleading in several ways.

If the number of spore bearers is to be determined, the plating test again fails to give correct results, since the ratio of the spore bearers to the total number of live bacteria fluctuates constantly.

The direct microscopic count of the bacteria in milk after Skar's or Brew's method is a little more accurate than the plating test. It cannot be made entirely accurate, chiefly because only an extremely small amount, viz.: much less than a drop, can be examined. Such a small amount gives inaccurate results for the reason that it does not represent the number of bacteria in the milk supply correctly.

Furthermore, the microscopic test, like the plating test, is expensive and requires the services of a professional laboratory man. A microscope costing at least $\$ 75.00$ cannot be turned over to a creameryman who has had no previous experience in such work. The time may come when every creamery manager will be required by law to pass an examination in bacteriology, chemistry, and milk hygiene before he is allowed to put up milk for infants, just as a pharmacist has to pass an examination in materia medica, chemistry, and dispensing before he is allowed to put up prescriptions. Such laws, in fact, are already in force in certain sections in Europe. For the present, however, we must take the creamerymen as they are and we cannot expect them to do scientific work of a high order, or at least not all of them. Therefore we must use a simple test, such as the reductase test, for the next twenty or thirty years to come, for this reason, and probably thereafter for other reasons.

The reductase test measures accurately the extent of bacterial activity, in the "Double Time Test," if the exact length of time required for decolorization is determined. This is a more valuable criterion to go by, in judging raw milk to be pasteurized, than the mere number of bacteria, since it shows the capacity of the bacteria for decomposing milk and for forming harmful decomposition products. Furthermore, the fact that hydrogen, hydrogen sulphid, and mercaptans generated by such organisms as the members of the coli-aërogenes group and the bacteria of putrefaction, decolorize the methylene blue in the reductase test, plainly shows that the reductase test indicates harmful decomposition, besides the mere extent of decomposition. That certain diseased conditions of the udder can be detected by the reductase test, is known. Under these circumstances, I am satisfied that the reductase test is a much more valuable index of the sanitary quality of raw milk to be pasteurized than the plating test. If the results of the plating test are in conflict with those of the reductase test properly carried out, it is merely one of the numerous confirmations of the fact that the plating test is unreliable as an index of the sanitary quality of such milk.

On agar, the milk bacteria can never develop those decomposition products which they would develop in milk. Consequently it is useless to employ agar as a culture medium if the nature and amount of those decomposition products are to be determined, as in the case of raw milk to be pasteurized. The only proper medium for milk bacteria is milk, in such a case. This is another reason why the reductase test is valuable. 
The reductase test never fails to detect any lack of cooling in summer, in raw milk. It also detects any admixture of dirt. To determine whether a rapid decolorization is due to lack of cooling or to dirt, the acidity test is made. If the acidity is considerably above normal, therefore considerably above 0.17 per cent, the rapid decolorization is due to lack of cooling. If not, it is due to dirt. It is understood, however, that these tests are made on fresh milk. If there is an interruption of transportation facilities and the milk is kept in the country several days, it is apt to show a high number of bacteria and a rapid decolorization when there was neither dirt nor lack of cooling. These abnormal and rare conditions are to be taken into consideration, if they occur, in distinguishing between lack of cooling and dirt, as above stated.

For pasteurized milk and pasteurized cream the reductase test is not recommended. The heat of pasteurization interferes with the test.

Cheese makers and others who desire to make the fermentation test will find that the apparatus furnished for the reductase test can just as well be used for the fermentation test, the only difference being that the blue solution is omitted and the temperature is lower, viz: $98^{\circ} \mathrm{F}$. or $75^{\circ} \mathrm{F}$, as may be desired.

It will be found convenient to have the standard methylene blue solution made in the city and to send it to the milk-receiving stations in the country. Likewise, any bacteriological tests for the purpose of determining how much of the standard solution is to be used for a given milk supply, may conveniently be made in the city. It will be noticed that the scientific work may easily be separated from the elementary work of making the tests on the milk samples, as the solution made in the city or the results of the plating test can easily be sent anywhere. This enables the creamerymen to get all the accurate results which scientific laboratory work may afford, without having to do the scientific part of the work themselves. Under these circumstances anybody can make the test in the country and expensive help is unnecessary, so far as the country is concerned.

It is obvious that the reductase test affords the greatest advantages in summer. Whenever the number of bacteria is excessive either from lack of cooling, or from dirt, or from any other cause, this test never fails to detect it. Milk dealers who are shipping milk to cities or towns where the number of bacteria is limited by law, will have no trouble in locating, by this test, those farmers whose milk exceeds the limit. This will enable them to live up to the bacterial limits in the cities and towns, since they can exclude the objectionable milk from their shipments.

The results of the reductase test generally agree better with the plating results in summer than in winter.

Officials would do well to adopt the reductase test as the official test. They cannot expect the milk dealers to use the plating test, since it is impractical and misleading. Some kind of a test will have to be adopted because without such a test, the milk dealers cannot live up to bacterial standards.

Creamerymen who ship milk to New York City are reminded that the present limit (1915) for Grade B milk, raw, is $1 \frac{1}{2}$ million bacteria per cubic centimeter, if the milk is to be pasteurized in the city. This corresponds to three hours in the "Double Time Test," just as it corresponds to $11 / 2$ hours in the "Single Time Test."

All creamerymen and others making the test are urged to study those sections in the pamphlet which are printed in bold type, and to post the tables which go with the pamphlet in the testing room for daily use. 
The color of the tubes should be observed in bright daylight, not at gas light or other artificial light, and the blank tube for comparison should not be omitted. The color can be seen best on a white background.

Bacteriologists who are called upon to regulate the amount of the standard methylene blue solution in accordance with their plating results, are reminded that the "Single Time Test" and the "Double Time Test" want to be regulated each independently of the other. It is not safe merely to use five times as much blue solution for the "Doube Time Test" as was found necessary for the "Single Time Test." Each test must be compared with plating results directly.

The reductase test, as improved, will be found to give correct results. In summer, the results agree so well with the plating results that the plating test itself, if it were made in the country, could not furnish any better results. While excessive numbers of bacteria are always detected, a moderate number of bacteria can escape detection only, if the test is not performed properly. Generally, whenever an inaccurate result is obtained, it is due to insufficient mixing of the milk sample. It is to be remembered that only a very violent agitation of the milk will break up the clumps of bacteria. If the sample is placed in a sterilized bottle, half filled, and the bottle shaken very vigorously 25 or 30 times, correct results are obtained every time. Can milk must be stirred vigor. ously before sampling.

Bacteriologists who compare plating results with the results of the reductase test, will find it convenient to use for the milk samples sterilized bottles of about six ounces capacity. Having the bottle only half filled, to make shaking easy, a good representative and well mixed sample is secured for both tests, and enough is left to repeat the tests, if necessary.

As the color test affords an easy means for detecting excessive numbers of bacteria, milk dealers need no longer run the risk of having their milk condemned by inspectors and of having their reputation ruined. If the color test shows that a given can of milk is above the legal limit for bacteria, all they have to do, is to send it to the churn instead of selling it as sweet milk. Or better still, they can make a contract with their farmers specifying that the milk furnished to them must not be decolorized, by the "Double Time Test," in less than 21/2 hours, or 3 hours, or 4 hours, as the case may be. As they are then at liberty to return the milk to the farmer, without loss to them, if it runs high in bacteria, they can make sure that their milk will always pass inspection. Milk dealers, in other words, need not dread the consequences of official inspection any longer. 


\section{Barthel's Reductase Test}

Improved by Hugo Jone

\section{Directions for Making the Color Test (Methylene Blue Test) for Bacteria in Milk}

Copyright 1915 by Hugo Jone

Most bacteria living in milk separate an enzym or body juice known scientifically by the name of reductase. The reductase has the property of destroying the blue color of the aniline dye known as methylene blue. If there are many millions of bacteria in a sample of milk, the large amount of reductase they separate is sufficient to decolorize at once the measured amount of methylene blue solution usually added to the milk for the test. If there are few bacteria, they do not separate enough reductase for decolorizing the methylene blue completely. However, if the bacteria are allowed to multiply by putting the milk in a warm place (usually 112 Fahrenheit), they will be so numerous in a few hours, that the reductase they separate is finally sufficient to decolorize the methylene blue completely. Manifestly, under these circumstances, a milk sample having many millions of bacteria in it, will be decolorized rapidly, while some samples having at the start only a few thousand bacteria in it, will require several hours for decolorization. Thus, we can tell the number of bacteria by the time required for decolorization. The samples must be kept at $112^{\circ} \mathrm{F}$. A convenient apparatus for keeping the samples warm is a double boiler provided with an alcohol lamp and a tube holder. The tubes with the samples remain in the warm water until decolorized. The inner pot of the double boile: may be used alone. 


\section{Apparatus used for the Improved Color Test.}

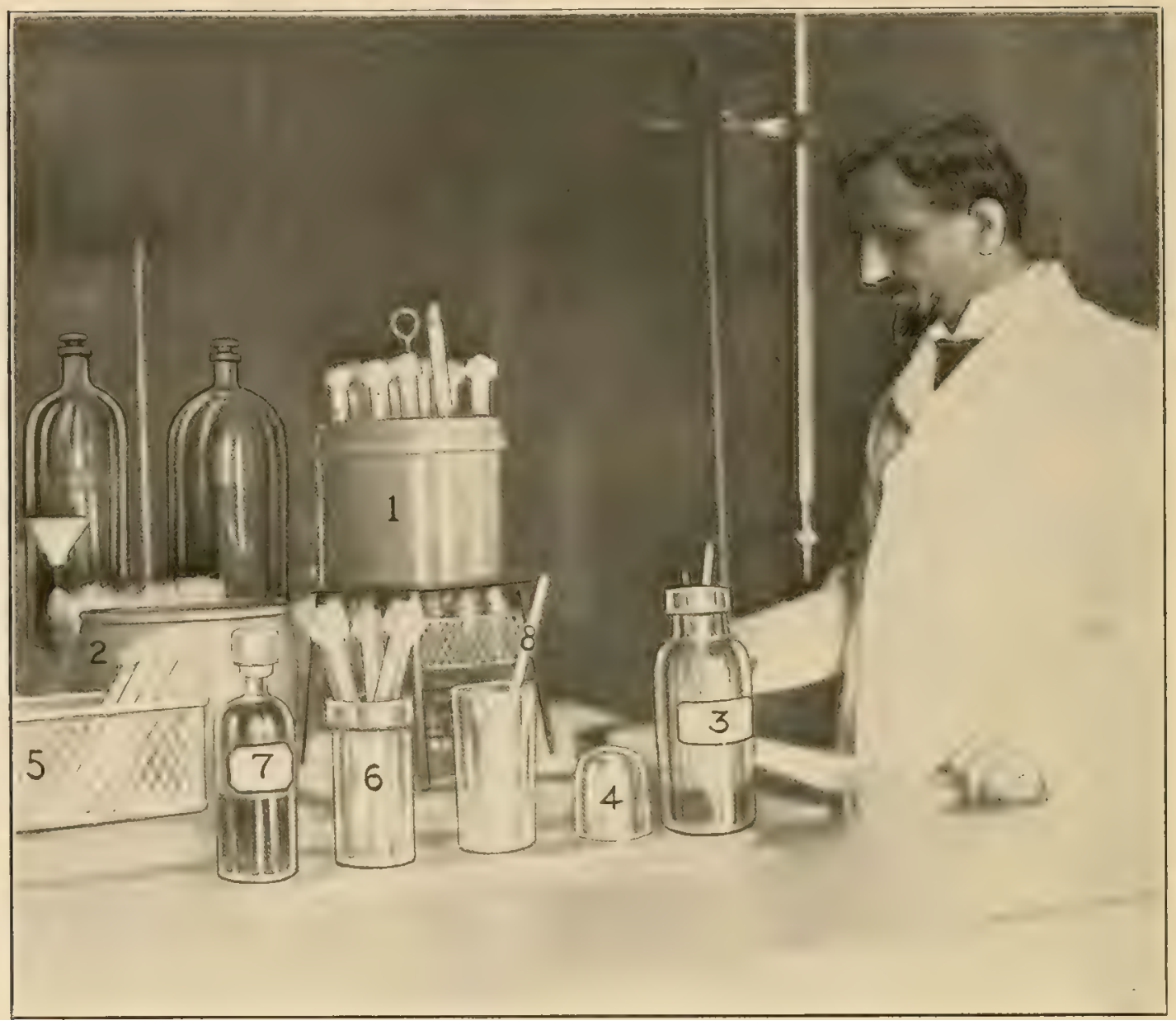

(1) The inner pot is seen standing on the tripod, with a test tube holder, test tubes, and a bulb thermometer on the inside of it.

(2) The outer pot is seen standing on the table.

(3) The methylene blue solution in use is contained in the wide-mouth bottle near the corner of the table next to the glass cap. (4) The glass cap is taken off only for the purpose of making both, the bottle and the cap, better visible. In the actual testing, the cap is never removed from the bottle except at the moment when solution is taken out of the bottle with the pipette. All dust is to be kept out of the blue solution that way. This style bottle is called an English oil bottle. It is especially well adapted for holding a pipette besides a liquid without polluting either.

(5) The wire basket with empty tubes, (6) the glass tumbler with decolorized tubes, (7) the pint bottle with mushroom glass stopper containing methylene blue solution ready for shipment, and other objects will be recognized without further specification.

The pipette fitted into the English oil bottle is a short nozzle pipette measuring 2 cubic centimeters of blue solution.

The other pipette (8) shown standing in one of the glass tumblers is a short nozzle pipette measuring 10 cubic centimeters of milk. As 20 cubic centimeters of milk are used for each test, the pipette must be dipped into the milk twice, instead of once, when sampling. This is done on purpose to secure a good average sample of the milk. 
The test is made as follows:-Enough warm water is placed in the outer pot of the double boiler to nearly fill the jacket formed when the inner pot is put inside, to insure uniform heating of the inside pot. Furthermore, in the inner pot enough water is put to submerge completely the milk samples in the test tubes, thereby insuring uniform heating of the milk samples. It would not do to have the milk in the tube stand higher than the surrounding water, because that portion of the milk column which sticks out above the water would cool off too much and in that way require more time than it should for decolorization.

The water in the inner as well as in the outer pot is brought to a temperature of $112^{\circ} \mathrm{F}$. The water in both pots is then continued at $112^{\circ} \mathrm{F}$. by means of the alcohol lamp.

The test tubes which contain 20 cubic centimeters of the different milk samples, each, and which are identified by the numbers on them, are then put into the water until they are as warm as the water, which is $112^{\circ} \mathrm{F}$. Then 2 cubic centimeters of the blue solution are dropped into each tube and mixed very thoroughly with the milk sample. A rubber stopper may be used to close the tube, to facilitate mixing. This can be cleaned by wiping it with a clean towel. However, the rubber stopper must be cleaned each time after use. If the towel is not strictly clean, it may spoil the succeeding tests. After mixing, each tube is closed with a cotton stopper.

After dropping the 2 cubic centimeters of blue solution into each of the tubes, the time is noted down, the color is observed, at fixed intervals thereafter, and the number of bacteria estimated by the time required for complete decolorization. The blue color must be turned into a plain white completely, except that at the top a faint blue ring may remain. There must be absolutely no blue color left at the bottom. If there is any, the mixing was not done thoroughly.

When observing the color of the tubes, they may be lifted out of the warm heater and placed into a wire basket having a layer of cotton at the bottom. However, they must be put back into the water immediately to prevent their cooling down too much.

The number of bacteria is estimated as follows: If less than ${ }^{\mathrm{I}}$ hour is required for decolorization, over 5 million bacteria, if hour, 3 to 5 million, if 3 hour, 2 to 3 million, if $1 \mathrm{~T} / 2$ hours, 1 to 2 million, if $2 \frac{\mathrm{I}}{2}$ hours, 300,000 to 1 million, if $3 \frac{\mathrm{I} / 2}{2}$ hours, 100,000 to 300,000 , if over 4 hours, less than 200,000 .

The tubes must be rinsed and then soaked in boiling hot water for at least 15 minutes after each use. If any milk adheres to a cotton stopper, it must be soaked off or washed off with hot water and the stopper dried thereafter.

Great care should be taken to keep the tubes at the proper temperature during the test. It must be $112^{\circ} \mathrm{F}$. A deviation of as much as 5 degrees will influence the result perceptibly. The color must never be dropped in until the temperature of the milk is $112 \mathrm{~F}$. or nearly so. If the milk is still cold, the time required for the decolorization will be unduly increased.

For the cotton stoppers, non-absorbent cotton should be used. It keeps clean longer than the absorbent cotton.

In testing high grade milk which is intended for infant feeding, it is generally necessary to keep the tubes in the warm water about twice as long as in the case of common market milk, since it takes longer to decolorize the clean milk.

The Health Department of New York City allows not more than 200,000 bacteria (determined by plating on agar) per cc in infant milk, or Grade A Milk, before pasteurization. Therefore this milk must remain blue at least 4 hours. It must, however, be remembered that this test gives only appruximate results, and is not as yet official. 
For Grade B Milk before pasteurization, the Health Department allows not more than $1 \frac{1}{2}$ million bacteria per $c c$. Therefore this milk must remain blue at least $1 \frac{1}{2}$ hours.

The strength of the methylene blue solution is of the utmost importance for the correctness of the test. A strong solution certainly requires more time to decolorize than a weak solution. Therfore, it must always have the exact strength, not more and not less. The testing and adjusting of the strength of the solution is to be left to a professional chemist, it being too technical for others. The strength of the solution is so regulated that the results obtained by the color test are about the same as those obtained by plating on agar. If they are not the same, the strength of the solution is corrected until they are the same.

The bottles containing the methylene blue solution must never be filled to the top, but only half filled. The solution keeps better in contact with air. Therefore, there must be an airspace in each bottle.

The time required for decolorization is to be reported by one of the following time limits :-

Less th
$I / 2$ hour
$3 / 4$ hour
$1 \mathrm{I} / 2$ hours
$2 \mathrm{I} / 2$ hours
$3 \mathrm{I} / 2$ hours
over 4 hours

In heating the apparatus with a lamp, only denatured alcohol or wood alcohol is to be used for burning. Never use gasoline, as it is liable to explode.

If the flame of the alcohol lamp flickers and the heating is irregular, the outside pot, if used, will maintain a fairly steady temperature in spite of the irregular heating. If on the other hand, the alcohol flame is protected from draught and not allowed to be extinguished or to flicker, the outside pot may be omitted, and the inside pot heated directly by the flame, in summer.

If in winter, the testing is done in a cold room, it is again desirable to use the outside pot besides the inside pot, for the reason that the water near the circumference of the inside pot would cool down rapidly and produce inaccurate results, if no jacket were used to keep the inside pot warm all over.

It will thus be seen that the outside pot can be eliminated only by regulating the flame, and in winter also the temperature of the room.

The outside pot may be used as a receptacle for the tubes when they are sterilized with hot water, at times when it is not needed as a jacket in the apparatus.

Before taking the samples of milk for the color test, the milk must be stirred sufficiently to mix the cream uniformly with the rest of the milk. If this is not done, too much cream goes into the samples and the results obtained are too high, as the cream contains more bacteria than the thin milk. Therefore, be sure to stir before sampling.

All tests should be made immediately after the samples are taken. If the samples are kept in a warm place before testing for more than half an hour, they will decolorize quicker and give incorrect results.

Whenever the capped bottle is filled with new solution, the remnant of the old solution in the bottle is to be wasted. It must not be mixed with the new solution. 


\title{
An Improved Methylene Blue Solution for the Reductase Test and Some Modified Forms of the Test
}

\author{
Copyright 1915 by Hugo Jone
}

The strength of the methylene blue solution used in the reductase test for the determination of the number of bacteria in milk, has in the past not received as much attention as it needs. Some of the failures to obtain correct results were due to the lack of a suitable apparatus, others were due to the application of European methods to American milk supplies without the necessary adaptation of those methods to American conditions, but most of the failures were due to the use of solutions which were either too dilute or too concentrated.

Confusion was caused by the use of different brands of methylene blue. Neither the make nor the label was specified. The alcoholic solution was sometimes fully saturated and sometimes only half saturated. Sometimes this solution was merely decanted or pipetted off, instead of being filtered, with the result that particles of solid methylene blue entered the diluted aqueous solution, making it far too strong. The moisture content of the alcohol varied, and the strength of the saturated alcoholic solution varied with it. Nearly every one of the experimenters used a solution of different strength, and yet, they were surprised when they obtained different results.

In addition to this, there were the differences in the milk supplies tested, such as are brought about by the seasons and by the differences in climate. As the production of reductase is associated chiefly with organisms growing well in summer heat, it is evident that we cannot possibly expect the same solution which gives correct results in summer, to give correct results in winter also. Yet some experimenters have applied the stummer solution to winter milk or the winter solution to summer milk in the vain hope of getting correct results.

These difficulties with the variations in the nature of the milk and in the strength of the solution are certainly more than sufficient to account for all the discrepancies which ever existed between the results obtained by the reductase test. Furthermore, they explain why this test has been so often and so unjustly denounced as unreliable. Before anybody declares the test to be unreliable, he certainly wants to determine first whether his own work is not unreliable. 
Neisser, Wechsberg, and Barthel deserve great credit for introducing the reductase reaction in practical milk testing, but they failed to put their method in a form which would enable the inexperienced operator to use it correctly.

All the difficulties with the strength of the solution may be overcome by preparing and standardizing it in the following manner:

\section{PREPARATION.}

About 10 grams of that brand of methylene blue which is labeled "Methylen Blau für Bac., Koch" and which is made by G. Grübler, Leipzic, are mixed with about $600 \mathrm{cc}$ of deodorized alcohol of the kind known as "Cologne spirits." The mixture is allowed to digest for twenty hours or longer at the ordinary room temperature. No harm is done if it is digested many months. It is advisable to shake the mixture from time to time to facilitate saturation. Just before using the mixture, however, it should be settled. $150 \mathrm{cc}$ of the clear, supernatant fluid are filtered, while the rest of the solution is retained for future use. $125 \mathrm{cc}$ of the filtrate, which must be perfectly clear and free from particles, are mixed with $275 \mathrm{cc}$ of Cologne spirits, and then the alcoholic mixture is mixed with enough distilled water to make ten liters. In other words, the diluted solution is made up as follows:

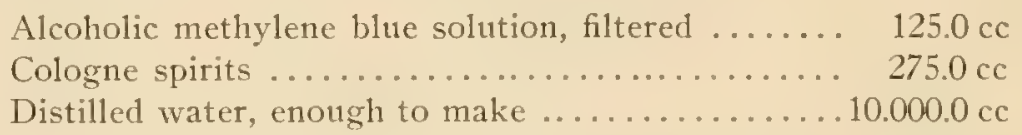

This solution must be standardized before it can be used for the reductase test.

\section{THE BACTERIOLOGICAL STANDARDIZATION.}

A few tests are made with this solution on samples of raw milk which are also tested by plating on agar. As the solution is still more concentrated than it is intended to be, the results obtained with the solution will, in most cases, be lower than the number of bacteria as determined by plating on agar. The solution must now be gradually diluted with distilled water until the results of the color test, when repeated, are about the same as those obtained by plating on agar. This correction of the strength of the methylene blue solution in accordance with the results obtained by plating is of the greatest importance for the success of the color test.

It is desirable to select raw milk from different sources for comparing the two tests.

A convenient way of making the comparison of the two tests is that of using the color test as a preliminary test for the plating. I need not point out the great need for a rapid test to indicate approximately the number of bacteria in the milk samples to be plated. Every bacteriologist knows that his results are incorrect if based on a plate having anything like a thousand or more colonies on it and that it saves him the making of three or four duplicate plates if he knows beforehand the approximate number of bacteria in each sample of milk to be plated. This advantage he secures by making, previous to the plating, the color test on the milk samples to be plated. In other words, he can determine what dilution to use in plating, by means of the color test. In less than three hours time, the color test will show him which of the samples contain an excessive number of bacteria and which, therefore, require a high dilution in plating.

By using the color test in this way, the additional advantage is secured of checking the strength of the methylene blue solution by the plating results. If the solution is found to give too low results, it is evident that the solution is too concentrated, as it generally will be when first made. Accordingly, as much distilled water is added to the solution as is thought necessary to have it give the desired results, or a little less 
water. Too hasty addition of water is to be avoided, because the solution would be worthless if it should become too dihute. If, upon repeating the comparative tests on similar samples, the solution is found to give results which are still too low, more distilled water is added and so on until it finally gives results which agree with the plating results. The strength of the solution thus found, is the correct strength to be used in testing milk supplies of a similar character.

After the methylene blue solution has thus been standardized, it will be found to give correct results on all similar samples of milk without any further correction of its strength. The color test can then be relied on as giving approximately the number of bacteria, no matter whether it is checked by plating or not.

Owing to this important advantage secured by the bacteriological standardization of the solution, this standardization should never be omitted whenever a new milk supply is tested the first time with the methylene blue. Thereafter it may be omitted so long as there is no material change in the nature of that milk supply. All that is necessary to do, is to leave the strength of the methylene blue solution unchanged.

If, however, the milk supply undergoes vital changes in its bacteriological contents, the solution must be re-standardized by comparison with plating results.

In the fall of the year, for instance, the decreased number of reductase producing organisms on the one hand, and the increased number of dead bacteria on the other hand, necessitate a re-adjustment of the strength of the solution. Correct results are again obtainable after the strength of the solution has been re-adjusted to conform to the new conditions.

It is evident that for similar reasons, a methylene blue solution which was found to give correct results on milk produced in Canada, cannot be expected to give correct results on milk produced in Mexico, until it is re-standardized by comparison with plating results.

It will be noticed that the sources of error which in the past have caused so much confusion and which have unjustly discredited the reductase test, are eliminated largely, if not entirely, by the proper preparation and the bacteriological standardization of the methylene blue solution. Not only is the strength of the solution regulated, but it is also regulated in a way which makes it impossible for changes in climate, or season, or locality to produce errors in the test. Likewise, the trifling amount of reductase which may occur in fresh milk immediately after milking and which was declared by some people to render the reductase test "worthless", can evidently not produce any material error in the results, since the amount of reductase in fresh milk is approximately constant, and since allowance is made for it in standardizing the solution.

It may be argued that different species of bacteria might produce different quantities of reductase and in that way influence the test. There is no evidence to show that those few species of bacteria which preponderate in milk, and which alone are numerous enougl to influence the test perceptibly, differ materially in their reductaseproducing capacity. The theory that different species might account for different results, was conceived for the purpose of explaining discrepancies which were in reality due to entirely different causes. It is to be remembered that the plating test itself is highly unreliable in its present form, as Conn has shown. It is therefore a poor criterion to go by.

It is understood that, if a magnifier is used to cottnt the colonies when standardizing the methylene blue solution by plating, such a magnifier must also be used afterwards if the results obtained by the color test are to be checked by plating. Likewise, the agar should be the same both times, and the method of diluting also. 
After the proper strength of the methylene blue solution has once been determined for a given milk supply, at a certain season, it is not necessary to repeat the bacteriological standardization each year when that season begins again. All that is necessary, is to use a solution of the same strength as was used the preceding year for the same season. In order to fix and continue the exact strength of the methylene blue solution, a chemical method is used which determines the strength of the solution with mathematical accuracy. The strength of the solution is expressed in numbers of cubic centimeters used up in a certain titration and the next year it is an easy matter for a chemist to make a solution of exactly the same strength even if he did not keep a sample of the solution from the preceding year. In this way, it is unnecessary to repeat the bacteriological standardization in all cases where milk supplies are to be tested which resemble each other as regards the season, or climate, or locality in which they were produced. A solution of the same strength, as determined by the chemical test, is used on all.milk supplies which are known to be similar.

\section{THE CHEMICAL STANDARDIZATION.}

The strength of the methylene blue solution may be measured accurately by tritrating it against a standard solution of stannous chlorid containing free hydrochloric acid. The blue solution is decolorized almost instantly when it touches the solution of stannous chlorid. This decolorization is analogous to the decolorization of the same solution in milk by reductase. It is due to the absorption, by the methylene blue, of hydrogen, and the formation of the leuco-compound, which is colorless. In the case of the stannous chlorid solution, the hydrogen is furnished by the breaking up of the hydrochloric acid molecule, while the chlorine combines with the stannous chlorid, forming stannic chlorid.

As soon as the whole of the stannous chlorid is converted into stannic chlorid, the blue color re-appears and remains permanent. Thus, the blue solution is its own indicator, which simplifies the titration. It is evident that the strength of the methylene blue solution can be measured by the amount of stannous chlorid oxidized, since the amount of hydrogen absorbed by the methylene blue is equivalent to the stannous chlorid oxidized.

In carrying out the titration, 11.8 milligrams of c. p. metallic tin in fine powder are dissolved in about $10.0 \mathrm{cc}$ of concentrated, c. p. hydrochloric acid with complete exclusion of atmospheric oxygen. A few crystals of carbonate of soda are dropped into the liquid contained in a $300.0 \mathrm{cc}$ Erlenmeyer flask which is closed by a rubberstopper carrying an india-rubber slit valve, also called "Bunsen valve." Manifestly the carbon di-oxid can pass outside, but the outside air cannot pass inside.

The dissolving of the tin may be hastened by putting the flask in a warm place. It must be watched to make sure that the whole of the tin is dissolved. When the solution is complete, the liquid is diluted with a suitable quantity of recently boiled distilled water (about $20 \mathrm{cc}$, free from oxygen) and the blue solution run in from a burette until the blue color just begins to remain permanent. During the titration the atmospheric oxygen is again kept away by dropping in a few more crystals of sodium carbonate when first opening the flask.

The volume of the methylene blue solution consumed in the titration with the stannous chlorid formed from 11.8 milligrams of tin, amounts generally to about $100.0 \mathrm{cc}$. However, as some milk supplies require strong methylene blue solutions, while others require weak solutions, as found by comparison with the plating results, the volume of blue solution consumed may be as low as $60.0 \mathrm{cc}$ or as high as $150.0 \mathrm{cc}$, for 11.8 milligrams of tin each. 
Chemists who keep a standard dichromate solution on hand, such as is used for the iodin number on fats or for the titration of ferrous salts, will find it convenient to prepare their stannous chlorid solution from the dry salt instead of dissolving the metallic tin, and to standardize the solution with their dichromate solution, using, if desired, potassium iodid and starch paste as indicator. A solution of suitable strength is obtained by dissolving about 100 milligrams of dry c. p. stannous chlorid in about $200.0 \mathrm{cc}$ of distilled water strongly acidulated with hydrochloric acid. The strength of the methylene blue solution in this case may easily be calculated from the amount of the metallic iron which had been consumed in checking the strength of the dichromate solution, remembering that, in these reactions, 11.2 milligrams of metallic iron are equivalent to 11.8 milligrams of metallic tin. It is convenient to use the same number of $\mathrm{cc}$. for standardizing the stannous chlorid solution with dichromate as is used for titrating the methylene blue solution. $30.0 \mathrm{cc}$ is a convenient amount in either case. It is to be borne in mind that these $30.0 \mathrm{cc}$ do not represent exactly 11.8 milligrams of metallic tin, and that the exact amount of tin they represent is to be determined. The calculation will thus be made easy.

No matter whether a dichromate solution is used or not, the strength of the methylene blue solution is always expressed by the number of cubic centimeters of the solution which correspond to 11.8 milligrams of metallic tin.

\section{THE COLORIMETRIC STANDARDIZATION.}

In place of the chemical standardization an easier method may be used to determine the strength of a methylene blue solution. It may be done by simply comparing the intensity of the color of such solution with that of a solution of known strength. The blue color, in other words, shows the strength of the solution, the shade of the color being proportional to the strength.

An exact comparison of the color of two solutions may be made by using two color comparison jars, known as Nessler jars. They are called Nessler jars from the fact that they are used extensively in sanitary water analysis for the determination of ammonia by the Nessler method. The best jars are those with polished bottom and uniform in clearness of glass and in shape.

In comparing the colors of two methylene blue solutions, the two jars are set on a small, flat mirror placed horizontally on a well illuminated table. If equal volumes of the two solutions are found by comparison to have different intensities, or shades, of color, the volume of the stronger solution is decreased by pouring out some of it. The colors are then compared again. If the stronger solution is still too dark, a little more is poured out until the colors of the two solutions are exactly equal in intensity. "When this is done, the height of the column of the stronger solution compared with the height of the column of the weaker solution shows how much stronger the former solution is than the latter and how much distilled water has to be added to it to make it equal in strength to the latter.

This test may be made correctly by any intelligent person from the directions given. The titration with stannous chlorid, on the other hand, should not be attempted by anybody who has not had a college course in quantitative chemical analysis, for it may lead to incorrect results in the hands of an inexperienced operator.

For most purposes, the colorimetric standardization is quite sufficient as a substitute for the titration. It is to be remembered, however, that the brands of methylene blue from which the two solutions are made, must be exactly the same. If the operator 
is not sure that they are the same, he should not apply the color comparison test or at least not rely on it. If, on the other hand, the two brands are the same, correct and fairly accurate results are obtainable by this test. It is inadvisable for any operator to use any brand of methylene blue other than that specified.

Frequently, the need arises of comparing a freshly prepared solution with an old solution. For instance, in the spring of the year, a solution may have to be made of exactly the same strength as the solution used in the spring of the preceding year. In this case it is absolutely necessary to see to it that the old solution has not lost any of its strength. If a solution is kept in a tightly stoppered bottle filled to the top, in a warm room, it will lose its color completely in the course of a few months. To prevent such a decolorization, either partial or complete, the solution is kept in bottles which are only half filled. The air re-oxidizes the solution. Furthermore, the sample of the solution which is to serve for color comparison the succeeding year, is preserved with corrosive sublimate besides being kept in a half filled bottle. A one grain tablet of corrosive sublimate of the kind manufactured by Eli Lilly \& Co., Indianapolis, and by similar firms, is quite sufficient to preserve 250 or $300 \mathrm{cc}$ of solution for many years. The white tablets are to be used, not those having an admixture of dye stuff in them.

Great care is to be taken that the corrosive sublimate is added only to those samples of solution which are to be preserved for color comparison, not to the ordinary testing solution which is added to milk samples. Although all the milk samples tested are wasted, a powerful chemical like corrosive sublimate should never be mixed with milk under any condition. The preserved solution should be kept locked up so it cannot be mistaken for ordinary testing solution. A poison label should be put on the bottle. The ordinary testing solution need not be preserved in that way. It retains its full strength several months, if it is kept in contact with air, even without a preservative.

While a solution of known strength is necessary to make the color comparison, no such solution is required in the titration with stannous chlorid. Furthermore, the titration with stannous chlorid need not be limited to any particular brand of methylene blue, as is the case with the color comparison. It can be applied to any kind or to any brand of methylene blue. The titration, therefore, has certain advantages. At the same time, it may be carried out without difficulty, by an experienced chemist.

The three methods of standardization above described, will, I should think, be quite sufficient to eliminate completely the serious errors which were formerly brought about by the lack of any method of standardization and other defects in the solution. Other improvements consist in the modification of the form of the test.

\section{THE DOUBLE TIME TEST.}

The directions for this test are printed in bold type in order to attract attention. While this form of the color test is very simple, it is nevertheless important. It will be found useful in most cases where milk or cream are to be tested for bacteria and is well suited for general adoption. This is the reason why special attention is called to this test.

If the color test is made with 8 (eight) cubic centimeters of methylene blue solution instead of 2 (two) cubic centimeters, the time required for decolorization amounts to about double the time required with 2 cubic centmeters. This is the reason why this test, made with 8 cubic centimeters, is called "the double time test".

This test offers two important advantages. It makes the blue color and the color changes much more conspicuous and it affords more accurate results. The disadvantage consists in that it takes twice as long, to learn the results of the test, which, how- 
ever, is not a serious drawback, except in certain cases. In the case of Grade B milk, or ordinary market milk, raw, the time required for making the test never amounts to more than eight hours and generally much less. Therefore, all such milk should be tested by the double time test. Likewise all raw cream.

Grade A milk or infant milk, raw, on the other hand, would require too long a time with the double time test. Therefore this kind of milk or any similar milk should be tested with only 2 cubic centimeters of blue solution, in other words, by the single time test.

Furthermore, a bacteriologist who uses the color test preliminary to plating for the purpose of determining what dilution he has to make, cannot afford to wait long enough for the results of the double time test. Therefore, he will do better to use only 2 cubic centimeters of the blue solution.

The double time test is made in exactly the same way as the single time test where only 2 cubic centimeters of blue solution are used. Having however 8 cubic centimeters, therefore four times as much, blue solution to mix with the milk sample, it is absolutely necessary to insert the rubber stopper and to shake the tube thoroughly each time. Otherwise the color is not distributed uniformly and gives incorrect results.

In the double time test as well as in the single time test, a blank tube must be put into the test tube holder along with the other samples. This blank tube contains only plain milk, without any blue solution whatever. The white color of this milk is compared with the color in the other tubes when they approach decolorization in order to determine whether there is a little blue color left or not. The exact time of decolorization can be determined more accurately that way.

In the double time test as well as in the single time test all samples must be wasted after the test is completed and the time is noted down. Not only those samples must be wasted which are still blue, but also those which have been decolorized.

As the time of the test is doubled when 8 cubic centimeters of blue solution are used instead of 2 cubic centimeters, the number of bacteria is estimated as follows:

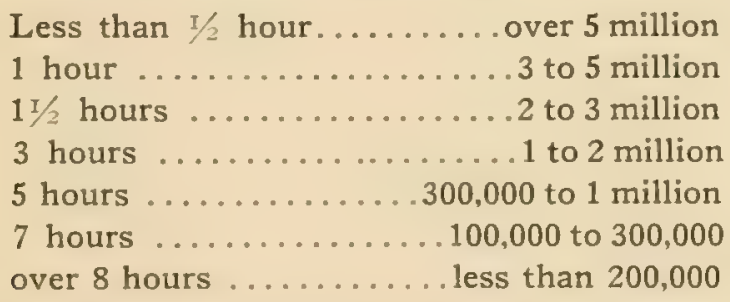

The results obtained in this manner are quite accurate and may be relied on as indicating correctly the extent of the bacterial activity in the milk. If, however, it be desired to get still more accurate results, this can be accomplished by observing the color of the tubes every half hour instead of every hour and reporting the results accordingly.

Milk dealers are advised to have their employees report merely the time required for decolorization and not the number of bacteria. As the time required for decolorization is quite sufficient to indicate the sanitary quality of the milk, it is unnecessary to figure out the number of bacteria each time, and besides, it is liable to lead to confusion with men who have had no experience in doing it. It is, however, necessary to state whether the double time test with 8 cubic centimeters of milk or the single time test with only 2 cubic centimeters of milk has been used. 
It is advisable to standardize the methylene blue solution for the double time test separately and to keep a separate solution for this test. However, if a separate solution is not available, the solution prepared for the single time test may be used or vice versa. As the strength of the two solutions is almost the same, no serious harm is done by substituting one for the other.

Raw cream may be tested in exactly the same way as raw milk.

\section{THE REDUCTASE NUMBER.}

While the number of live bacteria is indicated by the amount of reductase formed by them during the fermentation, at $112^{\circ} \mathrm{F}$. (about $45^{\circ} \mathrm{C}$.), the total number of bacteria, including the dead, is indicated by the amount of reductase present in a sample of milk without any such fermentation. In other words, the amount of reductase found in milk samples without incubation or fermentation, or previous to such fermentation, is approximately proportional to the number of bacteria as determined by the direct microscopic count after Brew's or Skar's method or a similar method. As some bacteriologists regard the direct microscopic count, which includes the dead bacteria, as a better index of the sanitary quality of milk than the determination of the live bacteria by plating, more especially in the case of raw milk to be pasteurized, where the live bacteria are killed anyway by subsequent pasteurization, it seems desirable to adopt some form of the reductase test capable of giving about the same results as are obtained by the direct microscopic count.

Accordingly, the total number of bacteria, including the dead, may be indicated rapidly by a direct determination of the reductase in a sample of raw milk without any fermentation. This can be done either by measuring the amount of blue solution decolorized within one minute, by a unit amount of milk, or by measuring the amount of milk necessary to decolorize, within one minute, a unit amount of blue solution. The latter method is the better, because the change of color is more distinct than in the other method, and because the large volume of milk can be measured more easily than the small volume of solution.

The method is carried out as follows:

$1.0 \mathrm{cc}$ of methylene blue solution of such strength that $100.0 \mathrm{cc}$ are required in the stannous chlorid titration, for 11.8 milligrams of tin, in a suitable, graduated tube, is put into the water bath of the color test apparatus kept at $112^{\circ} \mathrm{F}$. (about $45^{\circ} \mathrm{C}$.). A tubeful of the milk under examination is also put in. After both tubes have taken the temperature of the bath, the milk is added gradually to the blue solution and mixed with it until the blue color has completely disappeared. It is highly desirable to use a blank tube with plain, uncolored milk for comparison of colors, so as to recognize complete decolorization. The number of cc of milk required is the "reductase number".

A low reductase number indicates a high number of bacteria, while a high reductase number indicates a low number of bacteria.

With ordinary, raw market milk, the reductase number should not fall below 30 , with raw infant milk, not below 50 .

This test is found useful to indicate excessive numbers of bacteria, dead and alive, in cases where the operator has no time to wait for the result of the regular color test, more especially in summer.

Apparently, the reductase number is a correct measure of the extent of that decomposition in milk which is harmful to infants, in the case of raw milk to be pasteurized. While no particular accuracy is claimed for this test, it is quite sufficient to detect cxcessive decomposition, which is a material advantage. 


\section{THE METHYLENE BLUE SOLUTION OF STANDARD STRENGTH.}

Instead of varying the strength of the methylene blue solution to conform to the plating results, and leaving the amount of the solution constant, the amount may be varied and the strength left constant. For instance, instead of using $2 \mathrm{cc}$ of a solution of which $80 \mathrm{cc}$ correspond to 11.8 milligrams of tin, in the stannous chlorid titration, $2^{1}$ - $\mathrm{cc}$ of a solution of which $100 \mathrm{cc}$ correspond to 11.8 milligrams of tin, may be used. Likewise, instead of using $2 \mathrm{cc}$ of a solution of which $133.3 \mathrm{cc}$ correspond to 11.8 milligrams of tin, $1 \frac{1}{2} \mathrm{cc}$ of a solution of which $100 \mathrm{cc}$ correspond to 11.8 milligrams of tin, may be used. In each case, it will be noticed, a solution of the same strength, which is called "standard solution", may be used without altering the quantity of the dissolved, previously solid methylene blue, which is added to the milk sample or the result of the test, so long as the amount of the solution added is varied accordingly. If the standard solution is weaker than the solution to be replaced, it is evident that more of it has to be taken than was taken of the strong solution. If the standard solution is stronger, less of it is to be taken.

In this way, the advantage is secured of having to use only one kind of solution under any conditions, for any kind of milk, for any form of the test, the double time test as well as the single time test, and at any season of the year, viz.: the standard solution.

However, the operator who makes the tests must have proper appliances for measuring the varying amounts of the standard solution which may become necessary under varying conditions. For this purpose it is best to use short nozzle pipettes of the following capacities:

For the single time test:

In the winter............. $1 / 2 \mathrm{cc}$

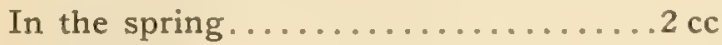

In the summer...............

In the fall .......................

For the double time test:

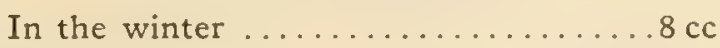

In the spring $\ldots \ldots \ldots \ldots \ldots \ldots \ldots \ldots . . .10 \mathrm{cc}$

In the summer ...............

In the fall................ $10 \ldots$

If these quantities of the standard solution are used as stated, the results obtained will be at least approximately correct without any further adaptation to plating results. More accurate results, however, can be secured by checking the results with plating results, as directed under the heading "Bacteriological Standardization," with this difference, however, that the plating results, which, in the other method, served to regulate the strength of the blue solution, are now used to regulate the amount of the solution instead. If, for instance, $10 \mathrm{cc}$ of the standard solution, in the double time test, are found to give too high results, the amount of the standard solution is increased to $12 \mathrm{cc}$, or even, if necessary, to $15 \mathrm{cc}$. If $10 \mathrm{cc}$ of the standard solution are found to give too low results, the amount is decreased to $8 \mathrm{cc}$ or even to $5 \mathrm{cc}$.

Likewise, in the single time test, the amount of the standard solution is to be increased from $2 \mathrm{cc}$ to $2 \frac{1}{2} \mathrm{cc}$ or even to $3 \mathrm{cc}$, or it may be decreased to $1 / 2 \mathrm{cc}$ or even to $1 \mathrm{cc}$, as the plating results may require.

It is difficult and unnecessary to tell beforehand how much more standard solution a given sample of milk will require in the double time test than in the single time test. 
Some milk supplies require 5 times as much, while others require only 4 times as much. Irrespective of this ratio, the capacity of the pipettes is to be determined by plating results.

In making the double time test with a standard solution, all the directions given for this test are to be carried out with the only exception that not always $8 \mathrm{cc}$ of the blue solution are used, but either more or less, as the season or the plating results may require.

In making the single time test with a standard solution, all the directions given for this test are to be carried out, with the only exception that not always $2 \mathrm{cc}$ of the blue solution are used, but either more or less, as the season or the plating results may require.

Attention is once more called to the fact that, when the standard solution is employed, the solution used for the double time test is exactly the same as that used for the single time test, the strength being standard strength in either case.

Whenever a standard solution is used, the chemical or colorimetric standardization precedes the bacteriological checking of the color test results. By "standard" solution is meant a solution of which exactly $100 \mathrm{cc}$ are required for 11.8 milligrams of tin, in the titration with stannous chlorid. Therefore, in preparing a "standard solution", this is the strength to be given to the solution.

Additional solutions of equal strength may then be prepared, at any time thereafter, by the colorimetric test, so long as the same brand of methylene blue is used, or the titration with stannous chlorid may again be employed to standardize such solutions.

After the standard solution is furnished for the color test, the plating tests on agar are made to determine how many $c c$. of the solution are to be used for any given milk supply, as stated, without changing the strength of the solution.

Under ordinary conditions, the standard solution offers greater advantages than the solutions of variable strength. It is therefore to be preferred. However, under unusual conditions, it is possible that the solutions with variable strength may give better satisfaction, for the reason that they obviate the necessity of changing pipettes. As creameries sometimes employ men who do not know the first thing about laboratory work, wrong pipettes are liable to be used in some cases. To preclude the possibility of such an error, it may possibly be best to furnish only one pipette to such men, even if it puts the bacteriologist or chemist to the trouble of preparing three or four different solutions each year.

As soon as the color test comes into general use, and is better understood, all creamery employees, including the less intelligent, will undoubtedly be able to use an entire assortment of pipettes correctly, and the exclusive use of the standard solution will then be in order.

\section{MATCHING EXTRAORDINARY PLATING RESULTS.}

The short nozzle pipettes of the capacities stated above will give about the same results as the plating tests, if the plating is done on standard infusion agar and the counting with the naked eye. If, on the other hand, beef extract agar containing 1.0 per cent of powdered, dry agar and 0.6 per cent of normal acid, is used, and the counting is done with a lens of $3 / 2$ cliameters magnification, short nozzle pipettes of the following capacities will deliver the proper amount of stanlard methylene blue solution to match the plating results: 
For the single time test:

In the winter ........... $1 \mathrm{cc}$.

In the spring $\ldots \ldots \ldots \ldots \ldots \ldots \ldots \ldots$

In the summer ......... $2 \mathrm{cc}$.

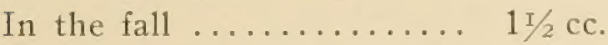

For the double time test:

In the winter ......... $5 \mathrm{cc}$.

In the spring $\ldots \ldots \ldots \ldots, 7 \mathrm{cc}$.

In the summer ........ $9 \mathrm{cc}$.

In the fall ............ $7 \mathrm{cc}$.

It is understood that the dilutions of the milk in the plating are such that not over 200 colonies develop on each plate. If considerably more develop, the counts are incorrect and the color test results can, therefore, not be expected to agree with them.

Furthermore, as near sighted persons get higher results than far sighted persons, in counting agar plates, the color test results cannot be expected to agree with the plating results, unless the counting is done by a person having normal eyes, or wearing correcting eye glasses. Likewise, on a bright day, the plating results run higher than on a cloudy day, since the small colonies are overlooked on a cloudy day. This is another case where the plating results, being incorrect, cannot always be matched by the color test.

Moreover, as rapidly growing bacteria decompose the milk more rapidly than others, the plating test fails to indicate correctly the extent of decomposition which the milk has undergone, since the small colonies formed by slowly growing bacteria are counted just the same as the large colonies formed by rapidly growing bacteria. The color test, for obvious reasons, indicates much better the extent of the decomposition and, therefore, it cannot be expected to agree with the results of the plating test, which, in the case of raw milk to be pasteurized, are misleading. This applies especially to cases where there are many small colonies on an agar plate, or else many large colonies.

That it would be a big mistake to condemn the color test merely because it sometimes fails to give the same results as the plating test, is most evident, I should think. With the plating test, errors are almost inevitable, but not with the color test.

\section{PROPOSED OFFICIAL MODIFICATION OF THE COLOR TEST.}

As soon as official limits are adopted on the color test, it will no longer be expected to follow the erratic fluctuations of the plating test. Color test results will have a meaning of their own, independent of the plating test. Their value will no longer be obscured by comparison with that test. It will then no longer be necessary to use different pipettes in the different seasons or otherwise to adapt the color test to the plating results. A $2 \mathrm{cc}$. pipette could be used for the single time test at any time of the year, and an $8 \mathrm{cc}$. pipette for the double time test, also at any time of the year. All official limits could be based on tests made with these two pipettes, with standard methylene blue solution, at a temperature of $112^{\circ} \mathrm{F}$. While it is possible to use a lower temperature, it does not seem desirable for the reason that low temperatures would bring out excessive numbers of the lactic acid bacteria and would generally fail to bring out those bacteria which are foreign to milk. The amount of standard solution, the temperature, and the permissible time of decolorization are to be specified with any official limits which may be adopted, since without these specifications, the limits would be indefinite. The varying conditions of the seasons, climatic conditions, and the distance of the milk producing districts from the city, these matters want to be taken into consideration in fixing official limits. The limits need not necessarily be the same for different cities. Furthermore, a summer standard and a winter standard is recommended for each city. The former. however, is naturally much more important than the latter.

The general official and private adoption of the color test is sure to come, for it will be found to afford very valuble results at a moderate expense. One operator can sample and test over 120 different lots of milk in 8 hours, while the plating test requires much more time. The color test will save thousands of infants. 


\section{THE COLOR TEST WITH EXCLUSION OF AIR.}

In the "Directions" it was stated that those tubes which had a blue ring at the top were to be regarded as decolorized so long as the rest of each tube was white. In doing so, correction is made for the blue colot re-formed from previously decolorized methylene bue by absorption of oxygen from the air. Instead of making this correction, the reformation of the blue color may be prevented altogether by excluding the air. This can be accomplished by using $30 \mathrm{cc}$ of milk instead of $20 \mathrm{cc}$, heating to $112^{\circ} \mathrm{F}$, as usual, adding the regular amount of methylene blue, dropping in enottgh sterilized glass beads to raise the level of the liquid to a point about half an inch from the top of the tube, and finally displacing the last remaining air space by inserting a perforated cork with a short, narrow glass tube in the centre to permit the escape of the air. The mixing of the blue solution with the milk is effected in the absence of air by slanting the tube in such a way that the glass beads drop from the bottom of the tube to the top and back again 6 or 8 times. The opening of the glass tube may be closed with a clean finger during the mixing. The test tube which is evidently brim full and deprived of air, is placed in the water bath as usual. As the growth of the aërobic organisms is restricted under these conditions, the decolorization requires about the same length of time with $30 \mathrm{cc}$ of milk as it would with only $20 \mathrm{cc}$ of milk and the same amount of methylene blue solution when in contact with air. For this reason, no more blue solution is used with the $30 \mathrm{cc}$ of milk. than with $20 \mathrm{cc}$ in the other form of the test, and the number of bacteria is estimated by the same tables. It is necessary, however, to add an "intermediary" test and table using twice as much blue solution as in the single time test, because the color is too faint if the single time test is used with $30 \mathrm{cc}$ of milk instead of $20 \mathrm{cc}$. Ordinarily, $4 \mathrm{cc}$ of blue solution are used with $30 \mathrm{cc}$ of infant milk, raw, and $8 \mathrm{cc}$ of blue solution with $30 \mathrm{cc}$ of common market milk, raw, unless a desire to match the plating results under abnormal conditions requires a modification of these amounts.

\section{The Intermediary Test, requiring irom $2 \mathrm{cc}$ to $6 \mathrm{cc}$ of standard methylene blue solution, as the p'ating results may indicate:}

Time required

for decolorization :

Less than 25 min.......... over 5 million

$3 / 4$ hour................. 3 to 5 million

1 hour................. 2 to 3 milion

2 hours............... to 2 million
Time required

for decolorization :

3 hours............ $1 / 2$ to $11 / 2$ million

4 hours.............200,000 to 800,000

5 hours.............. 100,000 to 300,000

over 6 hours......... less than 200,000

The corks and the glass beads, which should be $1 / 4$ to $1 / 2$ inch in diameter, are to be cleaned and sterilized after each test along with the test tubes. The cotton stoppers and the solid rubber stopper are no longer needed when the corks are used. In exact work, it is desirable to use sterilized glass beads not merely for the purpose of displacing the air and mixing the blue solution with the milk, but also for breaking up clumps in the uncolored sample before the $30 \mathrm{cc}$ are removed. The beads are shaken with the sample, which must be cold, 25 or 30 times. They must evidently be strained out later on, if any part of the sample is to be used for human consumption. Before the color is added, each sample should stand in the water bath 5 minutes to get warm and rid of air bubbles. There should be sufficient water in the bath to keep the tubes warm all the way from top to bottom. With milk samples which contain sediment, great care is to be taken to have the sediment distributed uniformly throughout the entire sample. Otherwise, incorrect results are obtained with any kind of test.

By excluding the air in the color test, uniform results are obtained because the amount of oxygen absorbed no longer varies. This form of the test is therefore to be preferred in all cases except where the operator is incompetent to use the glass beads and the corks without infecting the sample. Such operators may continue the air space in the tubes and get the best results possible for them by carefully avoiding any further agitation of the sample after the blue color has been mixed with it. Such agitation would evidently cause absorption of oxygen and spoil the results. As a preliminary test for plating, the "intermediary" test with $4 \mathrm{cc}$ of blue solution, and with exclusion of air, is better than any other test. The blue solution is to be kept in an ice box. 


\title{
The Apparatus
}

and the Standard Solution for the Color Test are kept for sale by the following dealers in bacteriological and chemical supplies:

\author{
EIMER \& AMEND, \\ 205 to 211 Third Avenue, \\ NEW YORK CITY.
}

\section{BAUSCH \& LOMB OPTICAL CO. ROCHESTER, N. Y.}

\author{
E. H. SARGENT \& CO. \\ 125-127 W. Lake Street, \\ CHICAGO, ILL.
}


LIBRARY OF CONGRESS 